\title{
Robotic-assisted abdominoperineal resection: technique, feasibility, and short-term outcomes
}

\author{
Solafah Abdalla1 ${ }^{1}$ Alain Valverde', Jean-François Fléjou², Nicolas Goasguen¹, Olivier Oberlin¹, Renato \\ Micelli Lupinacci ${ }^{1}$ \\ 'Service de Chirurgie Digestive, Groupe Hospitalier Diaconesses Croix Saint-Simon, Paris 75020, France. \\ ${ }^{2}$ Service d'Anatomie Pathologique, Hôpital Saint Antoine, Paris 75012, France.
}

Correspondence to: Dr. Renato Micelli Lupinacci, Service de Chirurgie Digestive, Groupe Hospitalier Diaconesses Croix SaintSimon, 125, rue d'Avron, Paris 75020, France. E-mail: rmlupinacci@gmail.com

\begin{abstract}
How to cite this article: Abdalla S, Valverde A, Fléjou JF, Goasguen N, Oberlin O, Lupinacci RM. Robotic-assisted abdominoperineal resection: technique, feasibility, and short-term outcomes. Mini-invasive Surg 2019;3:39. http://dx.doi.org/10.20517/2574-1225.2019.38
\end{abstract}

Received: 27 Sep 2019 First Decision: 12 Nov 2019 Revised: 29 Nov 2019 Accepted: 12 Dec 2019 Published: 26 Dec 2019

Science Editor: Nicola de'Angelis Copy Editor: Cai-Hong Wang Production Editor: Jing Yu

\begin{abstract}
Aim: The use of robotic-assisted laparoscopy seems fully adapted to pelvic surgery. However, few studies focus on robotic-assisted abdominoperineal resection (RAAPR). The aim of this study was to assess the feasibility, shortterm postoperative outcomes, and pathological results of RAAPR. In addition, we provide a detailed description of the operative procedure and a brief review of the current literature.
\end{abstract}

Methods: Between January 2013 and April 2018, we performed a total of 428 robotic surgeries, including 294 colorectal resections (68.7\%). Data were prospectively collected and included demographics, intraoperative findings, postoperative outcomes, and pathological data. For this study, we included the first 20 consecutive RAAPRs performed with the four-arm da Vinci Si surgical system (Intuitive Surgical Inc., Sunnyvale, CA, USA).

Results: Twenty patients (nine men) with a mean age of 68 years and a mean BMI of $24.5 \pm 5.0 \mathrm{~kg} / \mathrm{m}^{2}$ underwent RAAPR for low rectal adenocarcinoma (80\%) or squamous cell carcinoma of the anal canal. Sixteen (80\%) patients underwent preoperative pelvic radiotherapy and eight (40\%) had a history of previous abdominal surgery. Mean operative duration was $218 \pm 52 \mathrm{~min}$. There was no conversion to open surgery. Mortality, reoperation, and morbidity rate were $5 \%, 25 \%$, and $60 \%$, respectively. Three (15\%) patients presented perineal complications. Mean length of hospital stay was 20 days. Three (15\%) patients had pT4 tumor. Mesorectal excision was considered complete in $90 \%$. On average, $16.5 \pm 7.2$ lymph nodes were retrieved.

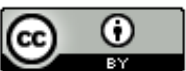

(C) The Author(s) 2019. Open Access This article is licensed under a Creative Commons Attribution 4.0 International License (https://creativecommons.org/licenses/by/4.0/), which permits unrestricted use, sharing, adaptation, distribution and reproduction in any medium or format, for any purpose, even commercially, as long as you give appropriate credit to the original author(s) and the source, provide a link to the Creative Commons license, and indicate if changes were made.

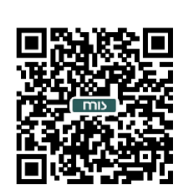


Conclusion: RAAPR is feasible, with acceptable pathologic and short-term outcomes. The current literature does not demonstrate significant differences between robotic and laparoscopic APR. Indeed, we cannot justify its use in routine on the basis on the available evidence.

Keywords: Abdominoperineal resection, total mesorectal excision, robotic surgery, feasibility, rectal cancer, anal cancer

\section{INTRODUCTION}

The frequency with which abdominoperineal resection (APR) is performed has dramatically decreased over the last decade, mostly due to technical advances, the need for shorter distal margins, and oncological therapeutic progress ${ }^{[1,2]}$. Despite this, APR remains the appropriate approach for rectal cancers with involvement of the sphincter complex or that cannot be removed with sufficient distal resection margins, and for elderly with poor baseline functional status ${ }^{[2]}$. Finally, APR remains the standard treatment for persistent or recurrent squamous cell carcinoma of the anal canal after chemoradiotherapy ${ }^{[3]}$.

Minimally invasive rectal surgery (MIRS) is a challenge ${ }^{[4]}$. The reported high conversion rates and the risks of positive circumferential resection margin (CRM) are thought to reflect the high level of difficulty associated with MIRS ${ }^{[5]}$. The fulcrum effect is one of the factors incriminated in the difficulty of MIRS, as it results in reduced motion ranges, especially inside the pelvis ${ }^{[6]}$. A robotic-assisted approach could potentially overcome some of the limitations of conventional laparoscopic rectal surgery ${ }^{[7]}$. However, few studies focus on robotic-assisted APR (RAAPR), and most are retrospective. Thus, the aim of this study was to provide a detailed description on the operative procedure, and to assess the feasibility, pathological, and short-term outcomes of the first 20 RAAPR in a high-volume center.

\section{METHODS}

\section{Patients' selection and preoperative management}

All consecutive patients undergoing RAAPR in our department from January 2013 to April 2018 were prospectively included. Patients with distant metastases were not excluded. Preoperative tumor staging assessment included colonoscopy; pelvic MRI; endorectal ultrasound when indicated; and thoracic, abdominal, and pelvic injected CT scan. Neoadjuvant treatment was planned according to the French guidelines $^{[8]}$ after multidisciplinary staff discussion.

\section{Postoperative care and follow-up}

Histopathological mesorectal grade was classified according to Quirke et al. ${ }^{[\rho]}$. All patients were started on clear liquids at postoperative day 1 , and then a soft diet on passage of gas in the stoma bag. Particular attention was made to the perineal wound healing. Patients were discharged once their pain was controlled on oral analgesics and when the healing of the perineal wound was considered satisfactory. No patient was included in any "Enhanced Recovery After Surgery" protocol. Surgical complications were evaluated during the 30-day postoperative period and were graded according to Dindo and Clavien ${ }^{[10]}$.

\section{Statistical analysis}

Demographic data, operative parameters, and pathologic outcomes were recorded in a prospectively collected database. Quantitative variables were expressed as means ( \pm standard deviation) and qualitative variables as frequencies (percentages). Statistical analyses were performed using SPSS (IBM SPSS Statistics, Version 23 for Macintosh; IBM Corp., Armonk, NY, USA). 
A All ports installed (classical placement)

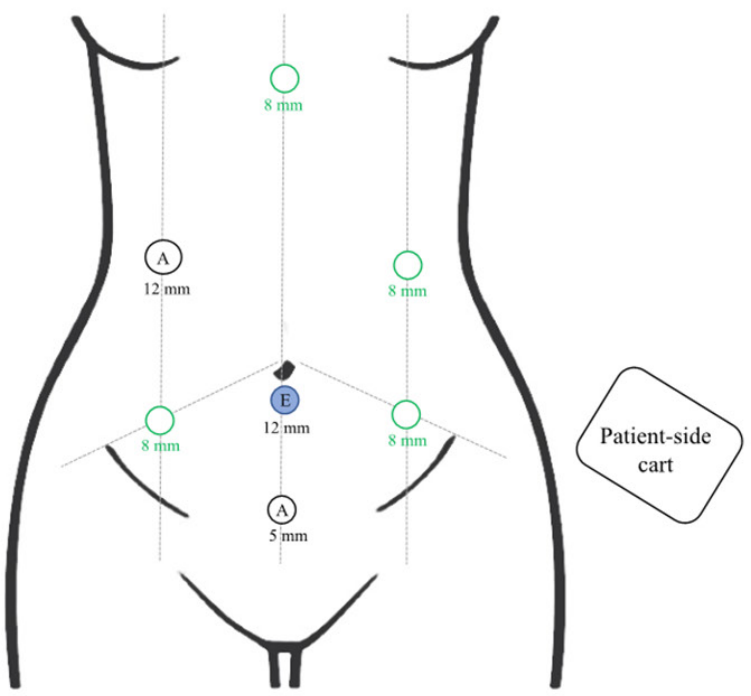

B All ports (alternatives)

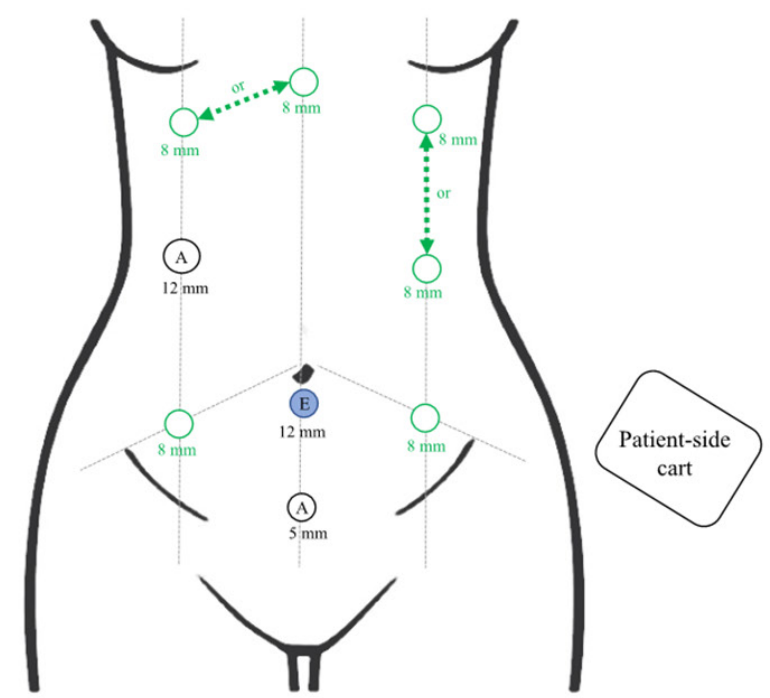

Figure 1. Port placement for robot-assisted abdominoperineal resection: operative view with all ports installed (A); and alternative placements of the ports (B). A: assistant port; E: endoscope port

\section{Robotic-assisted abdominoperineal resection technique}

The technique described below used a totally robotic colorectal mobilization and consisted of an up-todown approach (abdominopelvic, pelvic and perineal procedures), with cylindrical extralevator APR, using the four-arm da Vinci ${ }^{\otimes}$ Si surgical system (Intuitive Surgical Inc., Sunnyvale, CA, USA). The patient was placed in the lithotomy position, and the legs were placed in stirrups, in a $20^{\circ}$ tilted Trendelenburg and right-roll position. Transurethral or suprapubic catheter was placed.

\section{Port placement}

Seven ports were usually used, including one $12-\mathrm{mm}$ endoscope port, four 8 -mm robotic operative ports, and one $12-\mathrm{mm}$ and one $5-\mathrm{mm}$ laparoscopic ports for the assistant, with the cart placed obliquely at the left antero-superior iliac spine [Figure $1 \mathrm{~A}$ ]. The $12-\mathrm{mm}$ endoscope port was introduced through an infraumbilical incision; a $30^{\circ}$ endoscope was used for the abdominopelvic procedure, and then switched for a $0^{\circ}$ endoscope for the pelvic dissection. One 8-mm robotic port was placed at the level of the xyphoid process (Arm 2, abdominopelvic phase), another one in the right iliac fossa (Arm 1, abdominopelvic and pelvic phases), another in the left iliac fossa (Arm 3, abdominopelvic and pelvic phases), and the last in the left flank (Arm 2, abdominopelvic phase) [Figure 2]. A 5-mm laparoscopic port for the assistant was placed above the pubis and a 12-mm laparoscopic assistant port was placed in the right flank [Figures 1 and 2]. The xyphoidian 8 -mm port could be shifted in the right hypochondrium and the left flank 8-mm port could be placed in the left hypochondrium [Figure 1B].

\section{Exploration and robot docking}

The peritoneal cavity was explored to evaluate the presence of distant metastases (liver and peritoneal carcinomatosis). Adhesiolysis was performed laparoscopically if needed. The omentum was retracted to the supramesocolic compartment and the small bowel was retracted in the right side of inferior mesenteric vein axis in order to visualize the Treitz angle. The $30^{\circ}$ camera was placed in the $12-\mathrm{mm}$ port in the infraumbilical region, and robotic Arms 1-3 were placed in the right lower quadrant port, in the subxiphoid port, and in the left iliac fossa port, respectively. 


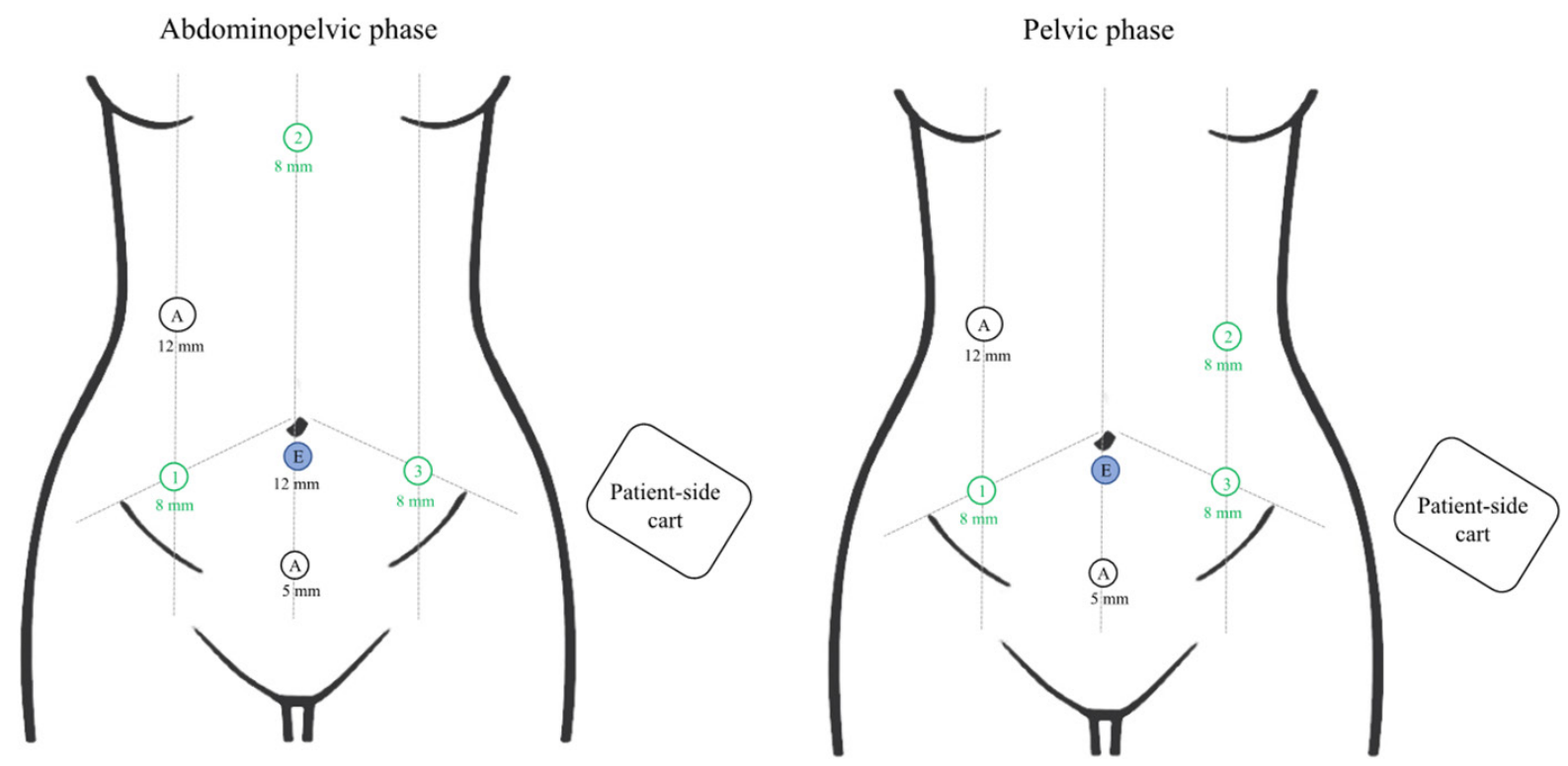

Figure 2. Port placement for robot-assisted abdominoperineal resection, in the abdominopelvic phase and in the pelvic phase. A: assistant port; E: endoscope port

\section{Abdominopelvic procedure}

The APR started with a medial to lateral approach. The mobilization of the splenic flexure and the ligation of the inferior mesenteric vein at its origin were usually not necessary. The peritoneum was incised at the level of the sacral promontory. The avascular presacral plane was entered, and this plane was developed identifying the origin of the inferior mesenteric artery and the left ureter. During this phase, dissection was performed using monopolar curved scissors (Arm 1), with tissues held by a Cadiere forceps (Arm 3), while the mesocolon was retracted using a fenestrated bipolar forceps (Arm 2). The superior rectal artery was ligated at its origin from the inferior mesenteric artery using a laparoscopic clip applier and cut. The mesenteric dissection was continued to the pelvic cavity along the prehypogastric fascia, preserving the pelvic autonomic nerves. The lateral approach was then performed with the incision of the Toldt's line, allowing complete sigmoid colon mobilization. The dissection was continued to the level of Gerota's fascia or the gastrocolic ligament, depending on the length of the sigmoid colon, and caudally to the level of the left peritoneal reflection. If the omentum was consistent, omentoplasty could be prepared by cutting right gastroepiploic vessels and mobilizing the omentum up to the left gastroepiploic pedicle.

\section{Pelvic procedure}

The pelvic procedure continued with TME. At this point, the switch of ports was required to carry on the procedure: Arm 2 was retrieved from the subxiphoid port and placed on the left iliac fossa port [Figure 2]. The pelvic dissection proceeded posteriorly first with the opening of the avascular presacral plane, then laterally, and finally anteriorly. Arm 3 was used for retraction, and Arms 1 and 2 were used to develop a plane of dissection between the presacral plane and the mesorectum until the Waldeyer fascia at the level of the anorectal junction. The rectal proper fascia was identified and preserved, and dissection was performed using robotic monopolar scissors. Then, lateral mesorectal dissection was performed. Particular attention was made to preserve hypogastric nerves. After the incision of the peritoneal reflection, lateral pelvic attachments were divided distally, until the levator ani. Lastly, the anterior mesorectal dissection was performed. The lateral peritoneal incisions were connected anteriorly at the recto-uterine pouch in women and rectovesical recess in men. Using Cadiere forceps to retract the urinary bladder and seminal vesicles, dissection was made to separate the rectum from the seminal vesicles and prostate or vagina through the Denonvillier's fascia, followed by separation of the levator muscles. When pelvic floor was reached 
Table 1. Preoperative characteristics

\begin{tabular}{ll}
\hline & Overall $(\boldsymbol{n}=\mathbf{2 0})$ \\
\hline Male (\%) & $9(45)$ \\
Age in years (mean \pm SD) & $68.5 \pm 14.1$ \\
Age $\geq 75$ years (\%) & $7(35)$ \\
$\mathrm{BMI}$ in $\mathrm{kg} / \mathrm{m}^{2}($ mean $\pm \mathrm{SD})$ & $24.5 \pm 5.0$ \\
$\mathrm{BMI}>30 \mathrm{~kg} / \mathrm{m}^{2}(\%)$ & $2(10)$ \\
$\mathrm{BMI}<18 \mathrm{~kg} / \mathrm{m}^{2}(\%)$ & $1(5)$ \\
$\mathrm{ASA}$ score $\geq 2(\%)$ & $17(85)$ \\
History of prior abdominal surgery (\%) & $8(40)$ \\
Indication of APR & \\
Low rectum adenocarcinoma (\%) & $18(90)$ \\
Epidermoid carcinoma of the anal canal (\%) & $2(10)$ \\
Pretreatment T4 tumor (\%) & $5(25)$ \\
Neoadjuvant treatment & $17(85)$ \\
Chemotherapy (\%) & $1(5)$ \\
Radiotherapy (\%) & $4(20)$ \\
Radio-chemotherapy (\%) & $12(60)$ \\
\hline
\end{tabular}

BMI: body mass index; APR: abdominoperineal resection

circumferentially around the rectum, the pelvic portion of the dissection was completed. The proximal portion of the colon was stapled and cut with an endostapler. A standard incision through the abdominal wall was then created at the intended colostomy site; the distal colon was brought through this incision; and the end colostomy was fashioned.

\section{Perineal procedure}

The perineal procedure was performed as previously described for open approach, in the lithotomy position (except for one patient, for whom it was performed in prone position because of hip dysplasia) ${ }^{[11]}$ : an elliptical incision was made around the anus outside the sphincter muscles. The ischiorectal fat was dissected until the levators plane was identified and cut. The section of the anococcygeal ligament gave access to the presacral space and the abdominal cavity. The specimen was extracted through the pelvic incision. Omentoplasty could be placed in the pelvic cavity at this point. The drains were positioned, and the perineal wound was closed.

\section{RESULTS}

\section{Patients' characteristics}

From January 2013 to April 2018, we performed a total of 428 robotic procedures, among which 294 colorectal resections (68.7\%), including 20 consecutive RAAPR. We included nine men (45\%). Mean age was $68.5 \pm 14.1$ years and mean BMI was $24.5 \pm 5.0 \mathrm{~kg} / \mathrm{m}^{2}$. Eight $(40 \%)$ patients had prior abdominal surgery (appendectomy in four patients, cholecystectomy in three patients, and suture repair of a perforated duodenal peptic ulcer in one patient). The majority of patients underwent APR for low rectum adenocarcinoma and 17 (85\%) patients received preoperative treatment. Demographic data are summarized in Table 1.

\section{Operative characteristics}

All patients underwent robotic-assisted rectal resection with TME and cylindrical extralevator APR with total excision of the levator muscle. The mean total operating duration was $218.1 \pm 52.5 \mathrm{~min}$. Mean operative console time was $96.2 \pm 48.0 \mathrm{~min}$ and perineal approach duration was $50 \pm 30.0 \mathrm{~min}$. Four robotic arms were used in $80 \%$ of the cases. Six ports were used in $70 \%$ of the patients. Fifteen (75\%) procedures required robotic arm realignment. Six (30\%) patients with fatty mesocolon required left colonic mobilization with section of the inferior mesenteric vein at its ending at the bottom edge of the pancreas, 
Table 2. Intraoperative characteristics

\begin{tabular}{ll}
\hline & Overall $(\boldsymbol{n}=\mathbf{2 0})$ \\
\hline Total operative duration in minutes (mean \pm SD) & $218.1 \pm 52.5$ \\
Operative console time in minutes (mean \pm SD) & $96.2 \pm 38.3$ \\
Proctectomy duration in minutes (mean \pm SD) & $96.2 \pm 48.0$ \\
Perineal approach duration in minutes (mean \pm SD) & $50 \pm 30$ \\
Number of robotic arms & \\
3 arms (\%) & $4(20)$ \\
4 arms (\%) & $16(80)$ \\
Number of ports & \\
4 ports (\%) & $3(15)$ \\
5 ports (\%) & $2(10)$ \\
6 ports (\%) & $14(70)$ \\
7 ports (\%) & $1(5)$ \\
Necessity of robotic arm realignment (\%) & $15(75)$ \\
Number of robotic arm realignment & \\
1 robotic arm realignment (\%) & $3(15)$ \\
2 robotic arm realignments (\%) & $12(60)$ \\
Splenic flexure mobilization (\%) & $3(15)$ \\
Section of the inferior mesenteric vein (\%) & $6(30)$ \\
Section of the inferior mesenteric artery (\%) & $11(55)$ \\
Total mesorectal excision (\%) & $20(100)$ \\
Specimen retrieval site & \\
Perineal incision (\%) & $19(95)$ \\
Supra-pubic incision (\%) & $1(5)$ \\
Omental pedicle flap placement (\%) & $5(25)$ \\
Associated procedures (\%) & $6(30)$ \\
Pelvic drainage (\%) & $20(100)$ \\
Conversion to open (\%) & 0 \\
Intraoperative complications (\%) & $2(10)$ \\
Bleeding (\%) & $1(5)$ \\
Tumor effraction (\%) & $1(5)$ \\
Intraoperative bleeding in mL (mean $\pm S D)$ & $297.5 \pm 420.0$ \\
\hline & \\
& \\
\hline
\end{tabular}

and splenic flexure mobilization for three (15\%) of them. Specimen retrieval was conducted through the perineal incision in $95 \%$ of the patients and all had terminal colostomy. Associated omentoplasty was performed in five $(25 \%)$ patients. The following associated procedures were performed in six $(30 \%)$ patients: incisional hernia repair $(n=1)$, resection of an ovarian cyst $(n=1)$, partial resection of the posterior wall of the vagina $(n=1)$, partial prostatectomy $(n=1)$, partial resection of the posterior wall of the prostatic urethra and urethroplasty $(n=1)$, and partial sacrectomy $(n=1)$. No conversion to open surgery was required in this series. Macroscopic intraoperative tumor effraction occurred in one patient (5\%). Mean intraoperative blood loss was $297 \mathrm{~mL}$. Intraoperative variables and outcomes are summarized in Table 2.

\section{Postoperative outcomes}

One patient (5\%) died at Postoperative Day 14 because of respiratory failure in the context of septic shock secondary to a Clostridium difficile colitis. Morbidity rate was 60\%, with seven (35\%) medical complications and nine (45\%) surgical complications. Six patients (30\%) presented a severe complication (Dindo-Clavien $\geq$ $3)$, which required reoperation in five (25\%). Perineal wound complication occurred in three (15\%) patients who presented complete disunion of the perineal wound and required iterative vacuum therapy until complete healing. These three patients had undergone preoperative 45 Gy pelvic irradiation and two of them had omental pedicle flap placement. The duration of hospital stay for these three patients was 29,65 , and 66 days, respectively. Four (20\%) patients presented pelvic abscesses, which were treated conservatively by antibiotherapy. Two patients $(10 \%)$ had ureteral fistula (one patient required reoperation and ureteral reimplantation, and the other was conservatively treated by ureteral catheter placement). The mean hospital length of stay was 20.4 days. Postoperative outcomes are summarized in Table 3. 
Table 3. Postoperative outcomes

\begin{tabular}{lc}
\hline & Overall $(\boldsymbol{n}=\mathbf{2 0})$ \\
\hline Mortality (\%) & $1(5)$ \\
Morbidity (\%) & $8(40)$ \\
Medical complications (\%)* ${ }^{\star}$ & $7(35)$ \\
Urinary tract infection (\%) & $5(25)$ \\
Acute urinary retention (\%) & $2(10)$ \\
Malnutrition (\%) & $2(10)$ \\
Pulmonary infection (\%) & $1(5)$ \\
Septic shock (\%) & $1(5)$ \\
Clostridium colitis (\%) & $1(5)$ \\
Ileus (\%) & $1(5)$ \\
Surgical complications (\%) & $9(45)$ \\
Pelvic abscess (\%) & $4(20)$ \\
Perineal wound disunion (\%) & $3(15)$ \\
Ureteral fistula (\%) & $1(5)$ \\
Incisional abscess (\%) & $2(10)$ \\
Clavien-Dindo $>2(\%)$ & $6(30)$ \\
Complications requiring reoperation (\%) & $5(25)$ \\
Hospital length of stay in days (mean \pm SD) & $20.4 \pm 17.1$ \\
Hospital length of stay > 7 days (\%) & $17(85)$ \\
\hline
\end{tabular}

${ }^{*}$ Several patients presented more than one complication

\section{Pathologic outcomes}

Pathological results are presented in Table 4. A complete pathologic response was observed in one patient (5\%). Three patients (15\%) presented a pT4 tumor on final pathological report. On average, 16.5 lymph nodes were retrieved. The mean tumor size was $4.6 \mathrm{~cm}$. Mesorectum was complete in 18 patients (90\%).

\section{DISCUSSION}

Our study showed that RAAPR is feasible, with satisfying pathological results and acceptable postoperative outcomes.

During the last decade, the use of the robotic system has progressed ${ }^{[12]}$. Proctectomy can be technically hazardous with the straight instruments and limited retraction provided by laparoscopy. Robotic-assisted pelvic dissection can be potentially associated with better autonomic nerve preservation, lower conversion rate, and less blood $\operatorname{loss}^{[13]}$. Despite its theoretical advantages, the benefits of the mini-invasive approach compared to open surgery in rectal surgery are still under debate, and it is even more questionable for the robotic approach ${ }^{[14]}$. Indeed, the only existing randomized clinical trial (ROLARR) comparing the roboticassisted $v$ s. conventional laparoscopic surgery for rectal cancer showed that the robotic approach did not significantly reduce the conversion rate ${ }^{[15]}$. There were also no differences between the two groups in terms of intraoperative complications, postoperative mortality and morbidity, and positive CRM. The interest of robotic assistance in APR is even more challenging to demonstrate since very few studies in the literature focus on RAAPR [Table 5]. We found only four studies that included more than 20 patients: three studies compared RAAPR to open $\mathrm{APR}^{[1,1,1]}$ or to open APR and laparoscopic $\mathrm{APR}^{[18]}$, and one non-comparative study $^{[19]}$ focused on RAAPR. The ROLARR trial, for its part, did not analyze the outcomes in its specific sub-population of 52 RAAPR.

Compared to the conventional laparoscopic approach, the benefits of the robotic upgraded handling on the patient outcomes are difficult to bring to light. Indeed, up to now, robotic assistance seems to remain equivalent to laparoscopy. In the current study, the operative duration was $218.1 \pm 52.5$, which is in line with the data in the literature [Table 5] and longer than laparoscopic $\mathrm{APR}^{[18]}$. No conversion was required 
Table 4. Pathologic outcomes

\begin{tabular}{|c|c|}
\hline & Overall $(n=20)$ \\
\hline \multicolumn{2}{|l|}{ Tumor regression grade $(n=15)$} \\
\hline No response (\%) & $3(25)$ \\
\hline Minimal (\%) & $7(35)$ \\
\hline Moderate (\%) & $3(25)$ \\
\hline Near total (\%) & $1(5)$ \\
\hline Complete (\%) & $1(5)$ \\
\hline \multicolumn{2}{|l|}{ Tumor histology } \\
\hline Adenocarcinoma (\%) & $18(80)$ \\
\hline Epidermoid carcinoma (\%) & $2(10)$ \\
\hline \multicolumn{2}{|l|}{ pAJCC stage } \\
\hline Stade $0(\%)$ & $1(5)$ \\
\hline Stade I (\%) & $1(5)$ \\
\hline Stade II (\%) & $6(30)$ \\
\hline Stade III (\%) & $10(50)$ \\
\hline Stade IV (\%) & $2(10)$ \\
\hline \multicolumn{2}{|l|}{ pT-category } \\
\hline pTO (\%) & $2(10)$ \\
\hline $\mathrm{pT1}(\%)$ & 0 \\
\hline pT2 (\%) & $2(10)$ \\
\hline pT3 (\%) & $13(65)$ \\
\hline pT4 (\%) & $3(15)$ \\
\hline \multicolumn{2}{|l|}{ pN-category } \\
\hline pNO (\%) & $10(50)$ \\
\hline $\mathrm{pN} 1(\%)$ & $4(20)$ \\
\hline pN2 (\%) & $6(30)$ \\
\hline \multicolumn{2}{|l|}{ pM-category } \\
\hline $\mathrm{pMO}(\%)$ & $18(90)$ \\
\hline pM1 (\%) & $2(10)$ \\
\hline Number of retrieved lymph nodes (mean \pm SD) & $16.5 \pm 7.2$ \\
\hline Number of metastatic lymph nodes (mean $\pm S D)$ & $1.9 \pm 2.9$ \\
\hline CRM positive, $\leq 1 \mathrm{~mm}(\%)$ & $4(20)$ \\
\hline CRM depth in $\mathrm{mm}($ mean $\pm \mathrm{SD})$ & $2.3 \pm 1.9$ \\
\hline Tumor perforation (\%) & $2(10)$ \\
\hline \multicolumn{2}{|l|}{ Mesorectal grade } \\
\hline Incomplete (\%) & $1(5)$ \\
\hline Nearly complete (\%) & $1(5)$ \\
\hline Complete (\%) & $18(90)$ \\
\hline Distal margin in $\mathrm{cm}($ mean $\pm \mathrm{SD})$ & $3.2 \pm 1.9$ \\
\hline Tumor size in $\mathrm{cm}($ mean $\pm \mathrm{SD})$ & $4.6 \times 3.9 \pm 0.3$ \\
\hline
\end{tabular}

in our study and Moghadamyeghaneh et al. ${ }^{[18]}$ showed a significantly decreased conversion rate for RAAPR compared to laparoscopic APR (5.7 vs. 13.4\%).

The robotic approach presents technical drawbacks, mostly associated with the loss of haptic feedback. Actually, despite the massive help of the immersive 3D overview, vibration, pressure, or shearing forces are not always apparent ${ }^{[13]}$. A recent analysis of 509,029 patients who underwent elective colectomy in the United States from 2009 to 2012 showed that the rate of iatrogenic complications was increased for robotic surgery ${ }^{[20]}$.

Noteworthy, the results presented here are worse than our previously published results for sphinctersaving procedures ${ }^{[2]}$. The morbidity rate was $60 \%$, with mainly perineal wound disunions and urinary complications. The mean length of hospital stay was three weeks, which is longer than in other studies in the literature [Table 5]. In this series, no patient was included in any "Enhanced Recovery After Surgery" program, and perineal wound complications were associated with longer hospital stay. Indeed, three 


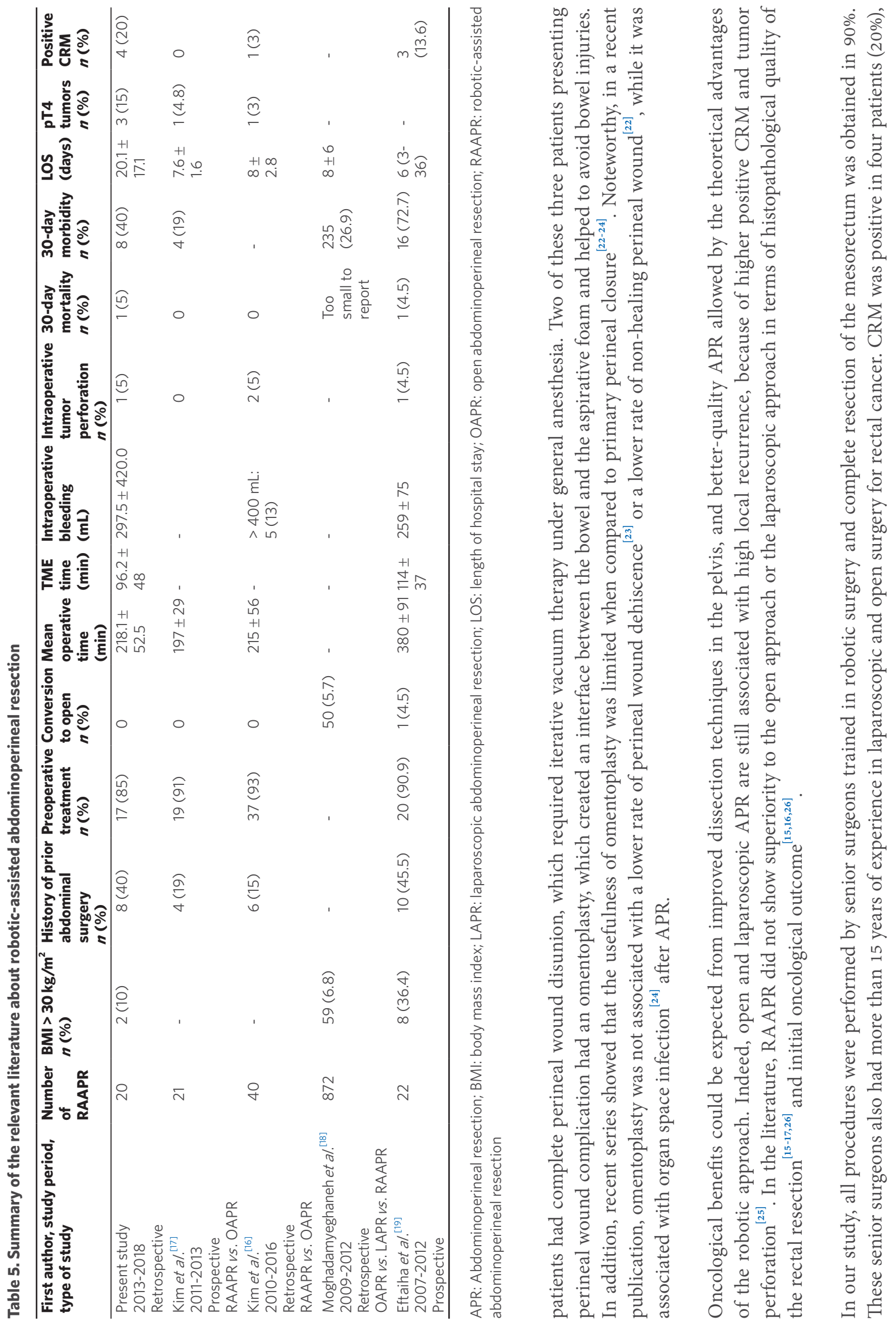


among whom two patients had a pT4 tumor. In our study, postoperative positive CRM was not suspected in the preoperative oncologic assessment for these patients. However, this high rate of positive CRM raises the issue of preoperative patients' selection. Upfront open APR could be chosen over RAAPR according to parameters that take into account the specificities of the robotic approach.

Any proposal for the routine utilization of robotic assistance in surgery requires a proof of clinical benefit, while considering the associated full set of costs. Indeed, even if MIRS has been shown to be associated with lower morbidity rate, reduced pain, and early return to work, there are not enough data to state that oncological results are equivalent ${ }^{[14]}$. Added to the difficulty in proving its clinical benefits, the use of robotic approach in APR outside clinical studies remains questionable.

\section{DECLARATIONS}

\section{Authors' contributions}

Data acquisition, data analysis, manuscript drafting, manuscript revision: Abdalla $S$

Data acquisition, manuscript revision: Valverde A, Fléjou JF, Goasguen N, Oberlin O

Study design, data analysis, manuscript drafting, manuscript revision, final approval: Lupinacci RM

\section{Availability of data and materials}

Not applicable.

\section{Financial support and sponsorship}

None.

\section{Conflicts of interest}

All authors declared that there are no conflicts of interest.

\section{Ethical approval and consent to participate}

This study was conducted according to the ethical standards of the local institutional committee on human experimentation and the consent form of all patients was obtained.

\section{Consent for publication}

Not applicable.

\section{Copyright}

(c) The Author(s) 2019.

\section{REFERENCES}

1. Bordeianou L, Maguire LH, Alavi K, Sudan R, Wise PE, et al. Sphincter-sparing surgery in patients with low-lying rectal cancer: techniques, oncologic outcomes, and functional results. J Gastrointest Surg 2014;18:1358-72.

2. Hawkins AT, Albutt K, Wise PE, Alavi K, Sudan R, et al. Abdominoperineal resection for rectal cancer in the twenty-first century: indications, techniques, and outcomes. J Gastrointest Surg 2018;22:1477-87.

3. Pesi B, Scaringi S, Di Martino C, Batignani G, Giudici F, et al. Results of surgical salvage treatment for anal canal cancer: a retrospective analysis with overview of the literature. Dig Surg 2017;34:380-6.

4. Jamali FR, Soweid AM, Dimassi H, Bailey C, Leroy J, et al. Evaluating the degree of difficulty of laparoscopic colorectal surgery. Arch Surg 2008;143:762-7.

5. Guillou PJ, Quirke P, Thorpe H, Walker J, Jayne DG, et al. Short-term endpoints of conventional versus laparoscopic-assisted surgery in patients with colorectal cancer (MRC CLASICC trial): multicentre, randomised controlled trial. Lancet 2005;365:1718-26.

6. Nisky I, Huang F, Milstein A, Pugh CM, Mussa-Ivaldi FA, et al. Perception of stiffness in laparoscopy - the fulcrum effect. Stud Health Technol Inform 2012;173:313-9.

7. Lanfranco AR, Castellanos AE, Desai JP, Meyers WC. Robotic surgery: a current perspective. Ann Surg 2004;239:14-21.

8. Cotte E, Artru P, Christou N, et al. (2019) “Cancer du rectum". Thésaurus National de Cancérologie Digestive. Available from https:// 
www.snfge.org/sites/default/files/SNFGE/TNCD/tncd_chap-05-cancer-rectum_2019-03-20_vf.pdf [Last accessed on 24 Dec 2019]

9. Quirke P, Dixon MF. The prediction of local recurrence in rectal adenocarcinoma by histopathological examination. Int J Colorectal Dis 1988;3:127-31.

10. Dindo D, Demartines N, Clavien PA. Classification of surgical complications: a new proposal with evaluation in a cohort of 6336 patients and results of a survey. Ann Surg 2004;240:205-13.

11. Perry WB, Connaughton JC. Abdominoperineal resection: how is it done and what are the results? Clin Colon Rectal Surg 2007;20:213-20.

12. Shah J, Vyas A, Vyas D. The history of robotics in surgical specialties. Am J Robot Surg 2014;1:12-20.

13. Sivathondan PC, Jayne DG. The role of robotics in colorectal surgery. Ann R Coll Surg Engl 2018;100:42-53.

14. Cleary RK, Morris AM, Chang GJ, Halverson AL. Controversies in surgical oncology: does the minimally invasive approach for rectal cancer provide equivalent oncologic outcomes compared with the open approach? Ann Surg Oncol 2018;25:3587-95.

15. Jayne D, Pigazzi A, Marshall H, Croft J, Corrigan N, et al. Effect of robotic-assisted vs conventional laparoscopic surgery on risk of conversion to open laparotomy among patients undergoing resection for rectal cancer: the ROLARR randomized clinical trial. JAMA 2017;318:1569-80.

16. Kim JC, Lee JL, Kim CW. Comparative analysis of robot-assisted vs. open abdominoperineal resection in terms of operative and initial oncological outcomes. Ann Surg Treat Res 2018;95:37-44.

17. Kim JC, Kwak JY, Yoon YS, Park IJ, Kim CW. A comparison of the technical and oncologic validity between robot-assisted and conventional open abdominoperineal resection. Int J Colorectal Dis 2014;29:961-9.

18. Moghadamyeghaneh Z, Hanna MH, Carmichael JC, Pigazzi A, Stamos MJ, et al. Comparison of open, laparoscopic, and robotic approaches for total abdominal colectomy. Surg Endosc 2016;30:2792-8.

19. Eftaiha SM, Pai A, Sulo S, Park JJ, Prasad LM, et al. Robot-assisted abdominoperineal resection: clinical, pathologic, and oncologic outcomes. Dis Colon Rectum 2016;59:607-14.

20. Yeo HL, Isaacs AJ, Abelson JS, Milsom JW, Sedrakyan A. Comparison of open, laparoscopic, and robotic colectomies using a large national database: outcomes and trends related to surgery center volume. Dis Colon Rectum 2016;59:535-42.

21. Valverde A, Goasguen N, Oberlin O, Svrcek M, Fléjou JF, et al. Robotic versus laparoscopic rectal resection for sphincter-saving surgery: pathological and short-term outcomes in a single-center analysis of 130 consecutive patients. Surg Endosc 2017;31:4085-91.

22. Blok RD, Musters GD, Borstlap WAA, Buskens CJ, Bemelman WA, et al. Snapshot study on the value of omentoplasty in abdominoperineal resection with primary perineal closure for rectal cancer. Ann Surg Oncol 2018;25:729-36.

23. Rencuzogullari A, Gorgun E, Binboga S, Ozuner G, Kessler H, et al. Predictors of wound dehiscence and its impact on mortality after abdominoperineal resection: data from the national surgical quality improvement program. Tech Coloproctol 2016;20:475-82.

24. Welten VM, Fields AC, Lu P, Goldberg JE, Irani J, et al. Omental flaps in patients undergoing abdominoperineal resection for rectal cancer. Int J Colorectal Dis 2019;34:1227-32.

25. Marr R, Birbeck K, Garvican J, Macklin CP, Tiffin NJ, et al. The modern abdominoperineal excision: the next challenge after total mesorectal excision. Ann Surg 2005;242:74-82.

26. Wang YW, Huang LY, Song CL, Zhuo CH1, Shi DB, et al. Laparoscopic vs open abdominoperineal resection in the multimodality management of low rectal cancers. World J Gastroenterol 2015;21:10174-83. 